\title{
PERSEPSI MASYARAKAT TERHADAP KEBERADAAN HUTAN MANGROVE DI KELURAHAN SETAPUK BESAR KECAMATAN SINGKAWANG UTARA KOTA SINGKAWANG
}

\author{
(Community Perceptions on Mangrove Forest in Setapuk Besar Singkawang Utara District \\ Singkawang City)
}

\author{
Masjuni Ayu, Hasan Ashari Oramahi, Sofyan Zainal \\ Fakultas Kehutanan Universitas Tanjungpura Pontianak, Jl. Daya Nasional Pontianak 78124 \\ Email: masjuniayu370@gmail.com
}

\begin{abstract}
Mangrove forest and the community lived around it are two components that influence each other. The interaction between the two of them is unavoidable because they live in the same environment. Activities, perceptions or actions of the community can affect the sustainability of the existence and the preservation of mangrove forest. This study aims to describe the community perceptions towards mangrove forest and to analyze the correlation that affects community perceptions in Setapuk Besar village towards the level of knowledge, dependence, and cosmopolitanism. The technique of sampling employed in this study is purposive sampling. Based on Slovin formula, a total sample of 74 respondents was obtained. The frequency of community perceptions in Setapuk Besar village on the existence of mangrove forest are: 67 respondents (90.5\%) had positive perceptions, 6 respondents $(8.1 \%)$ had neutral perceptions, and 1 respondent $(1.4 \%)$ had negative perception. From the results of Kendall tau-b test, the value of Sig $0.000<0.01$ and Sig $0.028<$ 0.05 , which indicates that there is a significant correlation between community perceptions with the level of dependence positive correlation (0.419), the correlation strength is moderate. Cosmopolitan level positive correlation (0.190), the correlation strength is low. While the value of Sig $0.170>0.05$, which indicates that there is no significant correlation between community perceptions and the level of knowledge positive correlation coefficient (0.119), the correlation strength is low.
\end{abstract}

Keywords: Community perceptions, mangrove forest, Respondents, Setapuk Besar.

\section{PENDAHULUAN}

Salah satu hutan mangrove di Kalimantan Barat terdapat di Kelurahan Setapuk Besar, Kecamatan Singkawang Utara, Kota Singkawang, Provinsi Kalimantan Barat dan di kelola oleh Perkumpulan Swadaya Peduli Mangrove (Septiandini dan Muflihati, 2019).

Hutan mangrove dan masyarakat yang bermukim di sekitarnya merupakan dua komponen yang saling mempengaruhi satu sama lain. Interaksi di antara keduanya merupakan bagian yang tidak dapat dipisahkan karena mereka berada dalam lingkungan yang sama. Aktivitas masyarakat sekitar hutan mangrove dapat mempengaruhi keberlanjutan keberadaan dan kelestarian hutan mangrove yang ada. Pertumbuhan penduduk yang tinggi dan meningkatnya kegiatan pembangunan di pesisir menyebabkan terjadinya tekanan ekologis terhadap ekosistem pesisir terutama ekosistem mangrove. Dampak terhadap kerusakan hutan mangrove baik secara langsung seperti kegiatan penebangan dan konversi lahan dan secara tidak langsung seperti pencemaran atau limbah berbagai kegiatan pembangunan pelabuhan. (Alimuna, 2009). 
Kadhapi dkk (2015) meneliti tentang persepsi masyarakat terhadap keberadaan hutan mangrove di Kawasan Pantai Air Mata Permai Kabupaten Ketapang, bahwa persepsi cenderung tinggi yaitu sebanyak $(57,78 \%)$. Tingginya persepsi masyarakat ini disebabkan oleh fungsi dan manfaat hutan mangrove secara tidak langsung keberadaan kawasan hutan mangrove memberikan dampak baik bagi alam dan lingkungan yang dirasakan oleh masyarakat.

Namun saat ini belum ada penelitian di Kelurahan Setapuk Besar Kecamatan Singkawang Utara Kota Singkawang tentang persepsi masyarakat terhadap keberadaan hutan mangrove. Permasalahannya adalah bagaimana persepsi masyarakat terhadap keberadaan hutan mangrove di Kelurahan Setapuk Besar. Berikutnya, apakah terdapat hubungan persepsi masyarakat Kelurahan Setapuk Besar terkait dengan tingkat pengetahuan, tingkat ketergantungan dan tingkat kosmopolitan. Berdasarkan permasalahan tersebut perlu dilakukan penelitian lebih lanjut untuk mengetahui persepsi masyarakat terhadap keberadaan hutan mangrove di Kelurahan Setapuk Besar Kecamatan Singkawang Utara Kota Singkawang. Penelitian ini bertujuan 1) mempelajari persepsi masyarakat terhadap keberadaan hutan mangrove di Kelurahan Setapuk Besar. 2) menganalisis hubungan yang berpengaruh antara persepsi masyarakat di Kelurahan Setapuk Besar terhadap tingkat pengetahuan, tingkat ketergantungan dan tingkat kosmopolitan.

METODE PENELITIAN
Penelitian ini dilaksanakan di Kelurahan Setapuk Besar Kecamatan Singkawang Utara Kota Singkawang. Penelitian ini dilakukan kurang lebih selama 1 bulan di lapangan mulai tanggal 28 Mei 2020 sampai dengan 28 Juni 2020. Terdapat tiga RT yang dijadikan responden yaitu RT 02, RT 03 dan RT 04 Kelurahan Setapuk Besar. Objek penelitian ini adalah Hutan Mangrove di Kelurahan Setapuk Besar dan subjek penelitian adalah masyarakat yang berada di sekitar hutan mangrove Kelurahan Setapuk Besar

Penelitian ini dilaksanakan secara purposive sampling menggunakan metode survey. Jumlah sampel responden yang diambil dalam penelitian ini disesuaikan dengan jumlah populasi yang ada dilapangan dengan karakteristik responden sebagai berikut:

1. Kepala keluarga yang berdomisili minimal 5 tahun di Kelurahan Setapuk Besar

2. Sehat jasmani dan rohani

3. Berada pada usia 20 tahun ke atas (lakilaki atau perempuan)

Penentuan jumlah responden dihitung menggunakan rumus slovin (Setiawan, 2007):

$\mathrm{n}=\frac{N}{1+N e^{2}}$

Keterangan :

$n=$ Ukuran / jumlah sampel

$\mathrm{N}=$ Ukuran / jumlah populasi

$\mathrm{e}=$ Batas kesalahan $/$ ketidaktelitian (persen kelonggaran 10\%)

Berdasarkan rumus Slovin tersebut didapat total 74 responden. Untuk lebih jelas dapat dilihat pada Tabel 1. 
JURNAL HUTAN LESTARI (2020)

Vol. 8 (4): 738 - 746 
Tabel 1. Jumlah sampel responden (The number of samples of respondents)

\begin{tabular}{cccc}
\hline No & Lokasi /RT & Jumlah Populasi (KK) & Jumlah Sampel \\
\hline 1 & RT 02 & 105 & 27 \\
2 & RT 03 & 112 & 29 \\
3 & RT 04 & 68 & 18 \\
\hline \multicolumn{2}{r}{ Jumlah } & $\mathbf{2 8 5}$ & $\mathbf{7 4}$ \\
\hline
\end{tabular}

Sumber: Data Primer 2020

Jenis data yang dikumpulkan dalam penelitian ini terdiri dari : 1) Data primer yaitu data mengenai persepsi masyarakat Kelurahan Setapuk Besar Kecamatan Singkawang Utara Kota Singkawang terhadap keberadaan hutan mangrove, yang akan dihubungkan menurut tingkat ketergantungan, tingkat pengetahuan dan kosmopolitan. 2) Data sekunder yaitu data penunjang yang berhubungan dengan keadaan lokasi penelitian, diperoleh dari instansi terkait yang menunjang hasil penelitian.

Data dianalisis dengan analisis deskriptif dan analisis inferensial. Analisis deskriptif digunakan untuk menganalisa data dengan cara mendeskripsikan data yang telah terkumpul sebagaimana adanya tanpa bermaksud membuat kesimpulan yang berlaku untuk umum atau generalisasi
(Sugiyono, 2004). Analisis inferensial dalam penelitian ini menggunakan uji statistik non parametrik korelasi Kendall Tau dengan tujuan untuk melihat hubungan antara variabel terikat (persepsi masyarakat terhaadaap keberadaan hutan mangrove di Kelurahan Setapuk Besar) terhadap variabel bebas yaitu (tingkat ketergantungan, pengetahuan dan kosmopolitan).

\section{HASIL DAN PEMBAHASAN}

Hasil peneitian yang telah dilakukan di Kelurahan Setapuk Besar diketahui bahwa persepsi masyarakat terhadap keberadaan hutan mangrove di Kelurahan Setapuk Besar Kecamatan Singkawang Utara, Kota Singkawang yang berjumlah 74 responden, dapat dilihat pada Tabel 2 .

Tabel 2. Frekuensi Responden Berdasarkan Persepsi Masyarakat (The frequency of respondents based on community perceptions)

\begin{tabular}{cccc}
\hline No & Persepsi & Frekuensi & $(\%)$ \\
\hline 1 & Positif & 67 & 90,5 \\
2 & Netral & 6 & 8,1 \\
3 & Negatif & 1 & 1,4 \\
\hline Jumlah & $\mathbf{7 4}$ & $\mathbf{1 0 0 , 0 0}$ & \\
\hline
\end{tabular}

Sumber : Analisis Data Primer 2020

Berdasarkan hasil penelitian yang telah dilakukan sebagaimana diuraikan dalam Tabel 2, di peroleh data frekuensi persepsi masyarakat di Kelurahan
Setapuk Besar terhadap keberadaan hutan mangrove , terdapat 67 responden $(90,5 \%)$ memiliki tingkat persepsi positif, sebanyak 6 responden $(8,1 \%)$ 
memiliki tingkat persepsi netral dan sebanyak $1(1,4 \%)$ responden tergolong ke dalam persepsi negatif.

Data menunjukkan tingkat persepsi masyarakat Setapuk Besar yang didominasi dengan tingkat persepsi positif dibandingkan persepsi netral dan negatif. Sebanyak 67 responden $(90,5 \%)$ memiliki tingkat persepsi yang positif terhadap keberadaan hutan mangrove di Kelurahan Setapuk Besar. Masyarakat memiliki persepsi positif adalah masyarakat dengan keinginan dan menyadari pentingnya hutan mangrove sebagai salah satu tujuan mensejahterakan taraf hidup mereka dan sebagai bentuk pelestarian lingkungan mereka dari berbagai dampak buruk yang akan ditimbulkan jika keberadaan hutan tidak dikelola dengan baik. Masyarakat dengan persepsi tinggi akan merasa terpengaruh dalam menentukan sikap dan tindakannya sehingga akan ikut berperan aktif dan berpartisipasi di dalam proses pembangunan. Sedangkan menurut Nilawati (2013), bahwa bila persepsi seseorang tinggi terhadap suatu hal, maka pengambilan keputusan akan selaras dengan persepsi tersebut ataupun sebaliknya.

Menurut Robbin (2006), persepsi merupakan penilaian atau tanggapan seseorang terhadap obyek atau kegiatan tertentu. Persepsi seseorang terhadap suatu obyek akan positif apabila sesuai dengan kebutuhannya, sebaliknya akan negatif apabila bertentangan dengan kebutuhan orang tersebut. Persepsi responden mengenai apa itu hutan mangrove adalah sebagai berikut: Hutan mangrove merupakan sumber daya kayu yang harus dimanfaatkan, hutan mangrove merupakan sumber pengetahuan masyarakat mengenai tempat wisata dan hutan mangrove sebagai pencegah abrasi. Keragaman persepsi responden menunjukkan adanya keragaman pengetahuan dan pemahaman masyarakat mengenai hutan mangrove bahkan juga terkait dengan adanya perbedaan aktifitas masyarakat dalam kehidupannya sehari-hari. Masyarakat yang aktifitasnya tergantung dengan hutan mangrove cenderung mempersepsikan hutan sebagai sumber ekonomi atau mata pencaharian, tetapi untuk masyarakat yang aktifitasnya tidak tergantung dengan hutan mangrove cenderung mempersepsikannya hutan sebagai sumber pengetahuan atau memahami bahwa hutan mangrove itu penting dan harus dijaga kelestariannya.

Analisis inferensial adalah analisis yang dilakukan dengan menggunakan uji ststistik serta digunakan untuk menganalisis data sampel dengan maksud membuat kesimpulan yang berlaku untuk umum (Idrus, 2009). Dari hasil uji statistik korelasi Kendall Tau dapat diketahui hubungan antara variabel terikat dan variabel bebas pada Tabel 3. 
Tabel 3. Hasil uji ststistik Kendall Tau (Kendall tau statistical test results)

\begin{tabular}{clcccc}
\hline No & Variabel & N & $\begin{array}{c}\text { Correlatio } \\
\text { Coefficient }\end{array}$ & $\begin{array}{c}\text { Sig.(2- } \\
\text { tailed) }\end{array}$ & Keterangan \\
\hline 1 & Ketergantungan & 74 & $0,419 * *$ & 0,000 & $\begin{array}{c}\text { Signifikan } \\
\text { Tidak } \\
2\end{array}$ \\
Pengetahuan & 74 & 0,119 & 0,170 & $\begin{array}{l}\text { signifikan } \\
\text { signifikan }\end{array}$ \\
\hline
\end{tabular}

Sumber : Analisis Data Primer 2020

Hubungan Tingkat Ketergantungan

Dengan Persepsi Masyarakat Terhadap

Keberadaan Hutan Mangrove di

Kelurahan Setapuk Besar

Hasil analisis korelasi melalui uji ststistik Kendall Tau didapat hubungan antara persepsi masyarakat terhadap keberadaan hutan mangrove di kelurahan Setapuk besar dengan tingkat ketergantungan memiliki hubungan yang signifikan. Data tersebut diperoleh dari nilai Sig.(2-tailed) 0,000 lebih kecil dari taraf signifikan $1 \%$ atau nilai sig. $0,000<0,01$ dengan keofisien korelasi positif sebesar 0,419 . Hal ini menunjukan bahwa hubungan tingkat ketergantungan masyarakat Setapuk Besar dengan persepsi masyarakat terhadap keberadaan hutan mangrove memiliki hubungan yang signifikan dan kekuatan hubungan yang sedang dengan hubungan kedua variabel yang searah, didukung dengan hasil frekuensi ketergantungan sebanyak 51 responden dengan persentase sebesar $(68,9 \%)$ termasuk dalam kategori sedang, sehingga dapat disimpulkan bahwa semakin tinggi tingkat ketergantungan yang dimiliki oleh suatu masyarakat maka semakin tinggi pula tingkat persepsinya.
Hubungan Tingkat Pengetahuan Dengan Persepsi Masyarakat Terhadap Keberadaan Hutan Mangrove di Kelurahan Setapuk Besar

Hasil uji statistik Kendall Tau hubungan antara partisipasi masyarakat dalam pengembanga kawasan TWA Tanjung Belimbing terhadap pendapatan masyarakat tidak memiliki hubungan yang signifikan dimana hasil tersebut dapat di lihat dari hasil nilai Sig.(2-tailed) 0,170 lebih besar dari taraf signifikan 5\% atau nilai Sig 0,170>0,05 dengan koefisen korelasi positif sebesar 0,119. Sehingga dapat disimpulkan bahwa hubungan antara persepsi masyarakat dengan tingkat pengetahuan tidak memiliki hubungan yang signifikan terhadap keberadaan hutan mangrove dengan kekuatan hubungan yang lemah dan hubungan kedua variabel searah.

Berdasarkan hasil pengamatan dilapangan dapat diketahui bahwa tingkat pengetahuan masyarakat Setapuk Besar cenderung sedang dengan persentase $(63,5 \%)$ dimana sebagian besar masyarakat berpendidikan tidak sekolah sampai SD. Persentase pengetahuan masyarakat yang tergolong kedalam kategori sedang tidak dapat menjamin tinggi rendahnya 
persepsi yang ada di dalam suatu masyarakat hal tersebut disebabkan karena latar belakang pendidikan tiap individu yang berbeda-beda sehingga membuat pemikiran dan pemahaman yang berbeda-beda pula. Pada penelitian Khadapi dkk (2015) juga menyatakan bahwa responden yang tingkat pengetahuan sedang cenderung memiliki persepsi yang tinggi terhadap keberadaan kawasan hutan mangrove. Kemudian Khairiansyah dkk (2018) menyatakan bahwa pengetahuan seseorang berpengaruh terhadap persepsi seseorang.

Hubungan Tingkat Kosmopolitan Dengan Persepsi Masyarakat Terhadap Keberadaan Hutan Mangrove di Kelurahan Setapuk Besar

Hasil analisis korelasi melalui uji ststistik Kendall Tau didapat hubungan antara persepsi masyarakat terhadap keberadaan hutan mangrove di kelurahan Setapuk besar dengan tingkat kosmopolitan memiliki hubungan yang signifikan. Data tersebut diperoleh dari nilai Sig.(2-tailed) 0,028 lebih kecil dari taraf signifikan 5\% atau nilai sig.0,000 < 0,05 dengan keofisien korelasi positif sebesar 0,190. Hal ini menunjukan bahwa hubungan tingkat kosmopolitan masyarakat Setapuk Besar dengan persepsi masyarakat terhadap keberadaan hutan mangrove memiliki kekuatan hubungan yang lemah dengan hubungan kedua variabel searah. Sebanyak 44 responden dengan persentase sebesar $(59,4 \%)$ termasuk dalam kategori sedang, sehingga diketahui bahwa semakin tinggi tingkat kosmopolitan yang dimiliki oleh suatu masyarakat maka semakin tinggi pula tingkat persepsinya.

Koefisien korelasi persepsi dengan tingkat kosmopolitan memiliki kekuatan hubungan yang lemah, hal tersebut disebabkan sebagian besar masyarakat berumur sekitar 40 sampai dengan 49 tahun. Pada umur tersebut responden cenderung memiliki kesibukkan untuk bekerja sehingga untuk mencari informasi yang lebih banyak tentang hutan mangrove masih sangat kurang. Masyarakat belom tertarik untuk mencari informasi yang lebih terhadap keberadaan hutan mangrove. Sedangkan hal yang sama juga disampaikan oleh Diniansyah dkk (2017) daya pilihnya sendiri atau perhatiannya untuk menerima informasi yang datang dari luar juga menentukan perbedaan tingkat kosmopolitan masyarakat.

\section{KESIMPULAN}

Berdasarkan hasil penelitian dilapangan diketahui bahwa :

1. Sebanyak 67 responden $(90,5 \%)$ memiliki tingkat persepsi tinggi, 6 responden $(8,1 \%)$ memiliki tingkat persepsi sedang dan sebanyak $1(1,4$ $\%)$ responden tergolong ke dalam persepsi rendah. Tingkat persepsi masyarakat Setapuk Besar yang didominasi dengan tingkat persepsi tinggi dibandingkan persepsi sedang dan rendah.

2. Persepsi positif pada responden terhadap hutan mangrove dikarenakan sebagian masyarakat telah menyadari pentingnya peranan hutan mangrove bagi kehidupan 
mereka. Hal ini dikarenakan masyarakat menyadari dan merasakan peran dan manfaat dari hutan mangrove yang ada di Kelurahan Setapuk Besar baik yang dirasakan secara langsung maupun tidak langsung.

3. Hasil analisis korelasi melalui uji ststistik Kendall Tau didapat hubungan antara persepsi masyarakat terhadap keberadaan hutan mangrove di kelurahan Setapuk besar dengan tingkat ketergantungan dan tingkat Kosmopolitan memiliki hubungan yang signifikan dengan taraf signifikan $1 \%$ dan 5\%. Sedangkan hubungan antara persepsi masyarakat terhadap keberadaan hutan mangrove di kelurahan Setapuk besar dengan tingkat pengetahuan memiliki hubungan yang tidak signifikan. Dengan koefisien korelasi pada tingkat ketergantungan yang bersifat positif dan tingkat pengetahuan dan kosmopolitan bersifat negatif.

\section{SARAN}

1. Adanya persepsi yang tinggi dari masyarakat Kelurahan Setapuk Besar terhadap keberadaan hutan mangrove, maka Pemerintah Kota Singkawang diharapkan dapat mengoptimalkan pengelolaan terhadap keberadaan kawasan hutan mangrove, sehingga secara langsung maupun tidak langsung akan meningkatkan perhatian, daya tarik dan minat masyarakat terhadap keberadaan kawasan hutan mangrove.
2. Untuk mewujudkan pengelolaan hutan mangrove perlu adanya penyuluhan dari dinas terkait, serta perlunya pemberdayaan untuk masyarakat yang berada di sekitar kawasan hutan mangrove.

\section{UCAPAN TERIMA KASIH}

Terima kasih penulis ucapkan kepada Kepala Lurah Setapuk Besar serta seluruh masyarakat yang terlibat dalam pengisian kuisioner sehingga penulis dapat mengumpulkan informasi dengan baik serta penulis mengucapkan terimakasih kepada dosen pembimbing dan dosen penguji yang selalu memberikan bimbingan dan masukkan demi melancarkan segala proses sehingga dapat berjalan dengan lancar dalam menyelesaikannya.

\section{DAFTAR PUSTAKA}

Alimuna W, Sunarto, Herumurti S. 2009. Pengaruh Aktivitas Masyarakat Terhadap Kerusakan Hutan Mangrove Di Rarowatu Utara Bombana Sulawesi Tenggara. Geografi Indonesia. 23 (2): 142-153.

Diniansyah S, Lumangkun A, Wardenaar E. 2017. Persepsi Masyarakat Desa Nusapati Terhadap Keberadaan Mangrove Kecamatan Sungai Pinyuh Kabupaten Mempawah. Hutan Lestari 5. (1): $19-27$

Idrus, M. (2009). Metode penelitian Ilmu Sosial. Yogyakarta: PT. Gelora Akasara Pratama.

Khadapi M, Hardiansyah G, Zainal S. 2015. Persepsi Masyarakat Desa Sungai Awan Kanan Terhadap Keberadaan Hutan Mangrove di Kawasan Pantai Air Mata Permai 
Kabupaten Ketapang. Hutan Lestari 3 (1) : 108 - 116.

Khairiansyah M, Zainal S, Nugroho J. 2018. Persepsi Masyarakat Terhadap Keberadaan Hutan Mangrove di Kelurahan Kuala Kecamatan Singkawang Barat Kota Singkawang. Hutan Lestari 6. (2) : $416-427$.

Mazlan, Kartikawati SM, Burhanuddin. 2019. Keanekaragaman Jenis Semut (Formicidae) Arboreal di Hutan Mangrove Kelurahan Setapuk Besar Kota Singkawang. Hutan Lestari 7. (3) : 999 - 1006.

Milunardi, Fahrizal, Iskandar. 2014. Partisipasi Masyarakat Sekitar Hutan Adat Sebagai Daerah Penyangga Sumber Air di Desa Menyabo Kecamatan Tayan Hulu Kabupaten Sanggau. Jurnal Hutan Lestari. Vol 02. No. 02.

Nilawati. 2013. Hubungan Antara Persepsi dengan Sikap Orangtua Terhadap Paud Khairunnisa Seberang Padang Kecamatan Padang Selatan Kota Padang. Jurnal Spektrum Pls. Vol 1 No 1:11. 2013.

Nutriwani R, Bachrun N, Joko N. 2017.Sikap Masyarakat Dusun Pasir Laut Terhadap Keberadaan Hutan Mangrove Di Dusun Pasir Laut Kecamatan Mempawah Hilir Kabupaten Mempawah. Jurnal Hutan Lestari Vol 5 No 2.

Robbins, Stephen P, Judge TA. 2006. Perilaku organisasi. Edisi Bahasa Indonesia. Jakarta. PT. Indeks Kelompok Gramedia.

Septiandini TN , Muflihati. 2019. Ekstrak Buah Bakau Rhizophora mucronata Lamk Sebagai
Pewarna Alami pada Kain Katun. Tengkawang 9. (1) : 1 - 13.

Setiawan N. 2007. Penentuan ukuran sampel memakai rumus slovin dan tabel krejcie-morgan: telaah konsep dan aplikasinya. Makalah disampaikan pada Diskusi Il

Sugiyono. 2004. Metode Penelitian Bisnis. Bandung. CV Alfabeta. 